\title{
CD27 sustains survival of CTLs in virus- infected nonlymphoid tissue in mice by inducing autocrine IL-2 production
}

\author{
Victor Peperzak, Yanling Xiao, Elise A.M. Veraar, and Jannie Borst \\ Division of Immunology, The Netherlands Cancer Institute, Amsterdam, The Netherlands.
}

\begin{abstract}
Immunity to infections relies on clonal expansion of $\mathrm{CD8}^{+} \mathrm{T}$ cells, their maintenance as effector CTLs, and their selection into a memory population. These processes rely on delivery of survival signals to activated CD8 ${ }^{+}$ $T$ cells. We here reveal the mechanism by which costimulatory CD27-CD70 interactions sustain survival of $\mathrm{CD8}^{+}$effector $\mathrm{T}$ cells in infected tissue. By unbiased genome-wide gene expression analysis, we identified the Il2 gene as the most prominent $\mathrm{CD} 27$ target gene in murine $\mathrm{CD8}^{+} \mathrm{T}$ cells. In vitro, $\mathrm{CD} 27$ directed IL-2 expression and promoted clonal expansion of primed $\mathrm{CD8}^{+} \mathrm{T}$ cells exclusively by IL-2-dependent survival signaling. In mice intranasally infected with influenza virus, $\mathrm{Cd} 27^{-/-} \mathrm{CD8}^{+}$effector $\mathrm{T}$ cells displayed reduced IL-2 production, accompanied by impaired accumulation in lymphoid organs and in the lungs, which constitute the tissue

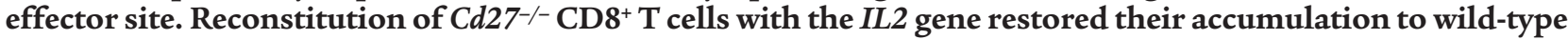
levels in the lungs, but it did not rescue their accumulation in lymphoid organs. Competition experiments showed that the IL-2 produced under the control of CD27 supported effector $\mathrm{CDB}^{+} \mathrm{T}$ cell survival in the lungs in an autocrine manner. We conclude that CD27 signaling directs the IL-2 production that is reportedly essential to sustain survival of virus-specific CTLs in nonlymphoid tissue.
\end{abstract}

\section{Introduction}

Control of $\mathrm{T}$ cell survival is essential for an adequate immune response (1). Throughout their life span, $\mathrm{T}$ cells find themselves in different cellular niches, where they may be resting or proliferating. The proliferative state is particularly stressful, since it may confront the T cell with DNA damage and deprivation of nutrients and/or oxygen, which are circumstances that potentially induce apoptotic cell death (2). In this light, it can be appreciated that various extracellular signals cooperate to regulate $T$ cell survival. To receive these survival signals, $T$ cells are equipped with an array of cell surface receptors that dynamically alters throughout the $\mathrm{T}$ cell response. The TCR, cytokine receptors and costimulatory receptors are particularly important in this respect (1-4).

$\mathrm{T}$ cell priming takes place in lymph nodes and spleen, which receive the antigen by means of DC delivery. Entry into the $\mathrm{G}_{1}$ phase of the cell cycle requires engagement of the TCR by MHCpeptide complexes $(5,6)$. This occurs in the context of T cell-DC communication, during which the DC also delivers costimulatory signals. Immature DCs express low levels of CD80 and CD86, which are upregulated upon DC activation (7). CD80 and CD86 are the ligands for CD28, a costimulatory receptor that signals by a similar mechanism as the TCR (5). TCR and CD28 signaling in conjunction set the threshold for $\mathrm{T}$ cell entry into $\mathrm{S}$ phase and actual cell division $(8,9)$. Data support the view that CD28 is a signal amplifier required for priming when TCR input is low, but not under conditions of high-dose antigenic stimulation $(5,6)$. Apart from initiating cell division, CD28 signals counteract apoptosis and regulate cell metabolism $(6,10)$.

CD28 signaling leads to increased expression of IL-2, a cytokine that is characteristically made by activated T cells (10). IL-2 can drive cell cycling via its multicomponent receptor, which in the

Conflict of interest: The authors have declared that no conflict of interest exists. Citation for this article: J. Clin. Invest. 120:168-178 (2010). doi:10.1172/JCI40178. high-affinity state consists of a unique $\alpha$ chain (CD25) and $\beta$ and $\gamma$ chains that are known to also be part of other IL receptors $(3,11)$. IL-2 has long been seen as the key mediator of cell cycle progression and T cell clonal expansion. However, TCR and CD28 signaling can also directly drive the cell cycle machinery and allow for IL-2-independent clonal expansion $(8,9,12)$. Whereas in vitro systems generally reveal a necessity for IL-2 in clonal expansion of primed CD8 ${ }^{+}$ $\mathrm{T}$ cells, it is now clear that the requirements in vivo are distinct (13, 14). In priming lymphoid organs, IL-2 is not required for initial division of $\mathrm{CD}^{+} \mathrm{T}$ cells, but it becomes essential during the late stage of expansion and is particularly important for maintenance of the effector $\mathrm{CD}^{+} \mathrm{T}$ cell pool at tissue sites $(12,15,16)$.

Apart from CD28, certain members of the TNF receptor family are important mediators of $\mathrm{T}$ cell costimulation, including CD27, 4-1BB, and OX40. TNF receptor family members employ a signaling mechanism that is distinct from the mechanism used by the TCR and CD28. They link to TNF receptor-associated factor (TRAF) family adaptors, which stimulate NF- $\mathrm{KB}$ and $\mathrm{c}-\mathrm{Jun}$ kinase signaling pathways (4). The NF-кB pathway is well known for its antiapoptotic effects, which proceed via transcriptional upregulation of Bcl-2 family members, c-Flip, and inhibitor of apoptosis proteins (17). In addition, these receptors may also activate the antiapoptotic protein kinase B pathway (18). The TNFrelated membrane-bound ligands of CD27 and related receptors are expressed on DCs, B cells, and T cells in a transient manner that depends on inflammatory and antigenic signals $(4,19)$. They therefore typically act in the context of an immune response. Many of the receptors are also induced upon immune activation. CD27, however, is already expressed on naive $\mathrm{T}$ cells and plays an important part during $\mathrm{T}$ cell priming (20).

Interaction between CD27 and its ligand CD70 is essential for the generation of a CTL effector pool after infection with various viruses, including influenza, vaccinia, and vesicular stomatitis virus (19-22). Upon intranasal infection with influenza virus, CD28 and 

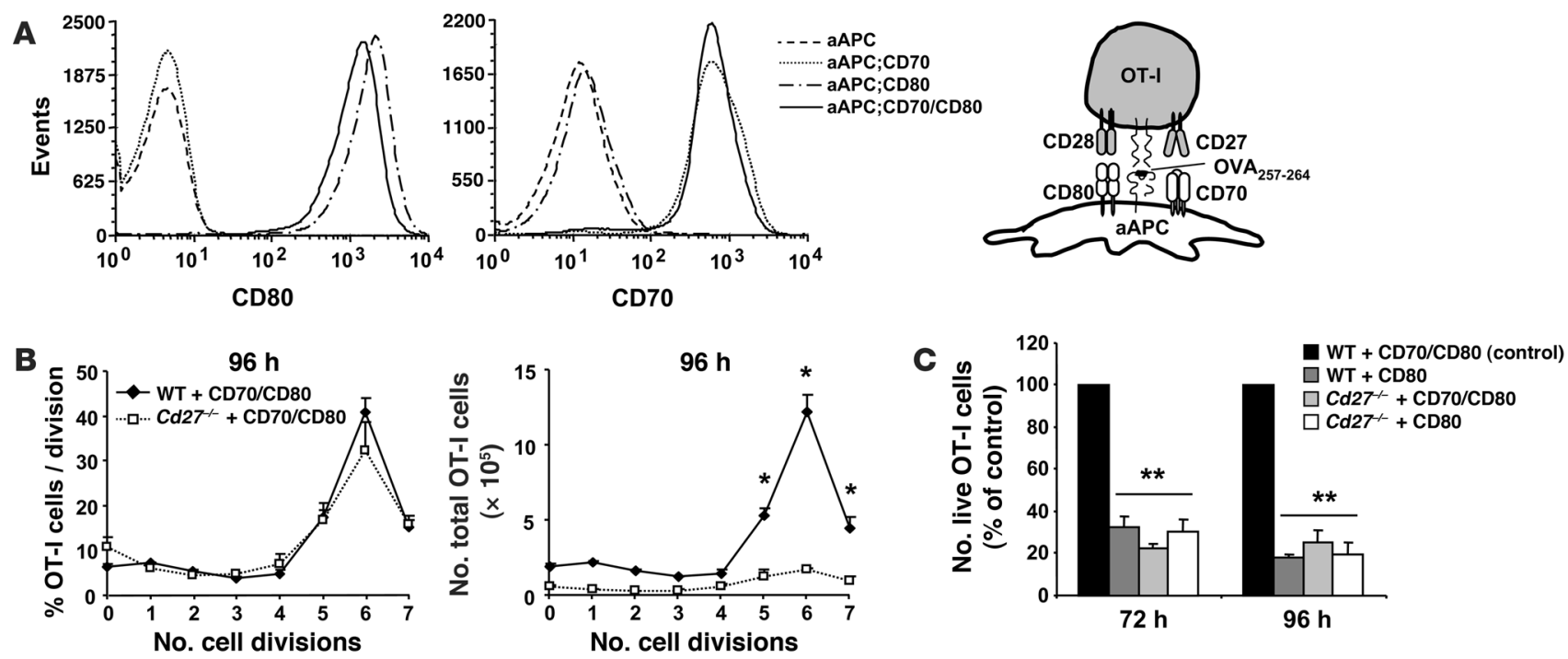

Figure 1

In vitro model of CD27-mediated T cell survival. (A) A mouse fibroblast line engineered to express the OVA $257-264$ peptide in the context of $\mathrm{H}_{-2} \mathrm{~K}^{\mathrm{b}}$ (26) was used as aAPCs for cognate OT-I CD8 ${ }^{+}$T cell priming in vitro. These cells were transduced to express CD70 and/or CD80 and flow cytometrically sorted on equal $\mathrm{H}-2 \mathrm{~K}^{\mathrm{b}}$ expression as schematically presented in the drawing. Histograms show CD80 and CD70 expression in MFI on the 4 indicated aAPC lines used. (B and C) Naive CFSE-labeled WT or Cd27-/- OT-I T cells were cocultured with the indicated aAPCs. Cells were counted and stained with TO-PRO-3, and CFSE dilution was determined by flow cytometry at 72 or 96 hours. (B) Left: Percentage of total $\mathrm{H}-2 \mathrm{~K}^{\mathrm{b}} / \mathrm{OVA}_{257-264}$ tetramer+ ${ }^{+} \mathrm{CD}^{+} \mathrm{OT}-\mathrm{I}$ cells in each cell division, as reflected by CFSE fluorescence intensity. Right: Absolute number of OT-I cells per division. Data are mean values + SEM of 4 samples and are representative of 3 independent experiments. ${ }^{*} P<0.005$, WT versus Cd27-/- $(t$ test). (C) The number of live OT-I cells present at 72 or 96 hours after priming, shown as percentage of control (WT + aAPC;CD70/ CD80). Data are mean + SEM of 4 independent experiments. ${ }^{* \star} P<0.0005$ versus control ( $t$ test).

CD27 made an equal contribution to clonal expansion of primed $\mathrm{CD}^{+} \mathrm{T}$ cells in the lung draining lymph nodes (DLNs). Moreover, CD27 was more important than CD28 for the accumulation of $\mathrm{CD}^{+} \mathrm{T}$ cells at the site of infection (20). In this mouse influenza virus infection model, CD27 sustained survival of $\mathrm{CD}^{+} \mathrm{T}$ cells throughout clonal expansion and at the tissue site but did not influence cell cycling (20). The survival signaling induced by CD27 is very potent, since transgenic expression of CD70 on steady-state DCs or $\mathrm{B}$ cells induced the (TCR-dependent) conversion of naive $\mathrm{CD} 4^{+}$and $\mathrm{CD}^{+} \mathrm{T}$ cells into effector cells, in the absence of deliberate immunization (23-25). Transgenic expression of CD70 on steady-state DCs could also break CTLA4- and PD1-dependent $\mathrm{CD}^{+} \mathrm{T}$ cell tolerance and convert it into potent antiviral (lymphocytic CMV) and antitumor immunity (23). The concept that emerges from this work is that CD27 signals, when superimposed on weak TCR/CD28 signals, keep activated $\mathrm{T}$ cells alive and allow them to differentiate into effector cells, whereas they would otherwise be deleted.

To elucidate the mechanism of CD27-mediated prosurvival effects, we employed genome-wide expression profiling of activated $\mathrm{CD}^{+} \mathrm{T}$ cells. We found that $\mathrm{Il} 2$ is a key CD27 target gene both in vitro and in vivo and that IL-2 is the mediator of CD27-directed $\mathrm{CD}^{+} \mathrm{T}$ cell survival during clonal expansion in vitro. Using genetic reconstitution of primary $\mathrm{T}$ cells and adoptive transfer in an influenza virus infection model, we demonstrate that CD27 mediates the survival of $\mathrm{CD}^{+}$effector $\mathrm{T}$ cells at the tissue site by stimulating autocrine IL-2 production.

\section{Results}

CD27-CD70 interactions promote survival of primed $C D 8^{+} T$ cells in vitro. To define the mechanism of CD27-mediated CD8 ${ }^{+} \mathrm{T}$ cell survival, we made use of an in vitro stimulation system. Engineered mouse fibroblasts that present $\mathrm{OVA}_{257-264}$ peptide in the context of $\mathrm{H}-2 \mathrm{~K}^{\mathrm{b}}$ (26) were equipped with CD70, CD80, or both and used as artificial APCs (aAPCs) (Figure 1A). As responder cells, H-2Kb/OVA $257-264^{-}$ specific OT-I TCR transgenic T cells were used that were either WT or genetically deficient for CD27. This experimental protocol allowed us to examine the contribution of CD27 costimulation to $\mathrm{CD}^{+} \mathrm{T}$ cell priming in the presence or absence of CD28 input. OT-I $\mathrm{T}$ cells were labeled with CFSE, cocultured with the aAPCs for 20 hours, and subsequently cultured in the absence of these cells. At 72 or 96 hours after initiation of stimulation, T cell yield, viability, and division were determined. As shown previously for murine $\mathrm{CD}^{+}$ $\mathrm{T}$ cells after in vitro stimulation with anti-CD3 and -CD28 mAb or after in vivo priming by influenza virus infection (20), CD27-CD70 interactions promoted overall live cell yield but did not detectably impact on cell cycle entry or activity of primed $\mathrm{CD}^{+} \mathrm{T}$ cells (Figure 1, B and C): the extent of OT-I T cell division based on CFSE dilution was equal in WT and Cd27-/- OT-I cells at all time points examined (Figure 1B and Supplemental Figure 1; supplemental material available online with this article; doi:10.1172/JCI40178DS1). However, at both 72 and 96 hours, live WT OT-I cells had accumulated to greater numbers than $C d 27^{-/-}$OT-I cells (Figure 1C). A similar contribution of CD27-CD70 interactions to accumulation of live OT-I T cells was seen when WT OT-I cells were stimulated with $\mathrm{CD}^{+} 0^{+}$aAPCs that did or did not express CD70 (Figure 1C). In this experimental system, OT-I T cells did not expand unless CD28-CD80 interactions were in place (data not shown). In summary, CD27-CD70 interactions significantly increased the survival of primed OT-I T cells, as determined by varying either responder $\mathrm{T}$ cells or aAPCs. These results indicated that the experimental sys- 
A

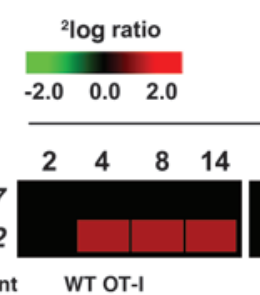

Constant WT OT-I

Comparison $\mathrm{CD}^{\circ} 0^{*}$ vs $\mathrm{CD}^{-}$

aAPC (-CD80)
B
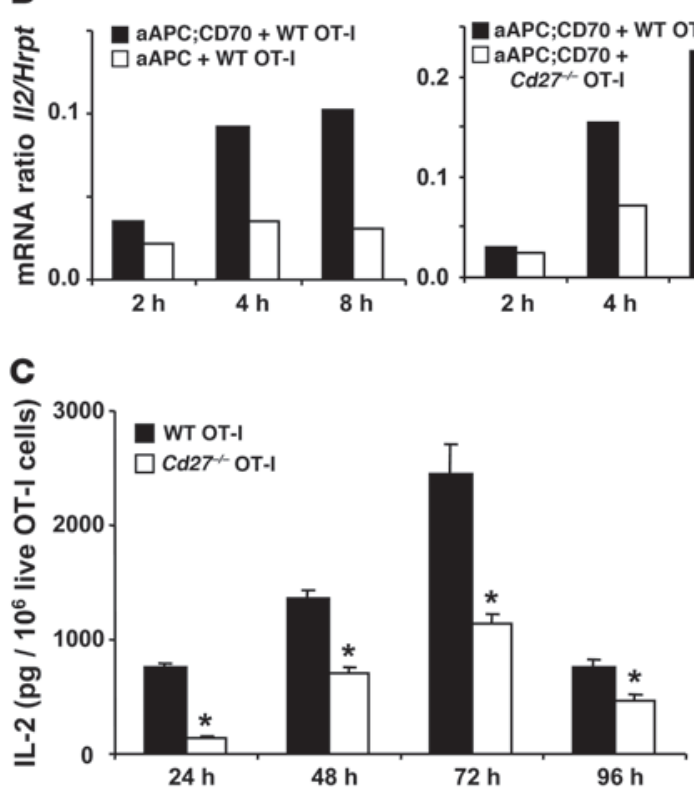

In vivo (d)
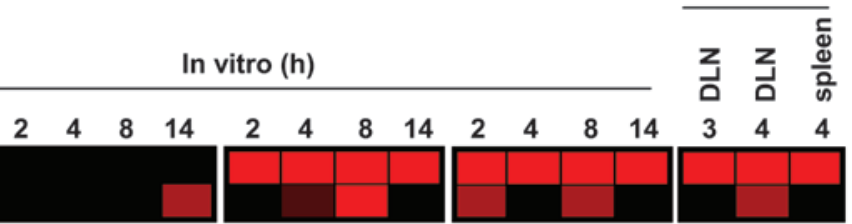

WT OT-I

CD70+ vs CD70aAPC (+CD80)
In vitro (h)

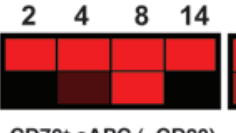

CD70+ aAPC (-CD80)

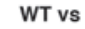

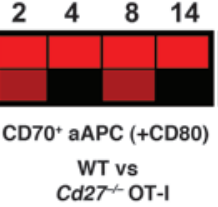

Cd27 OT-I
Cd27 $7^{\circ}$ OT-I
D
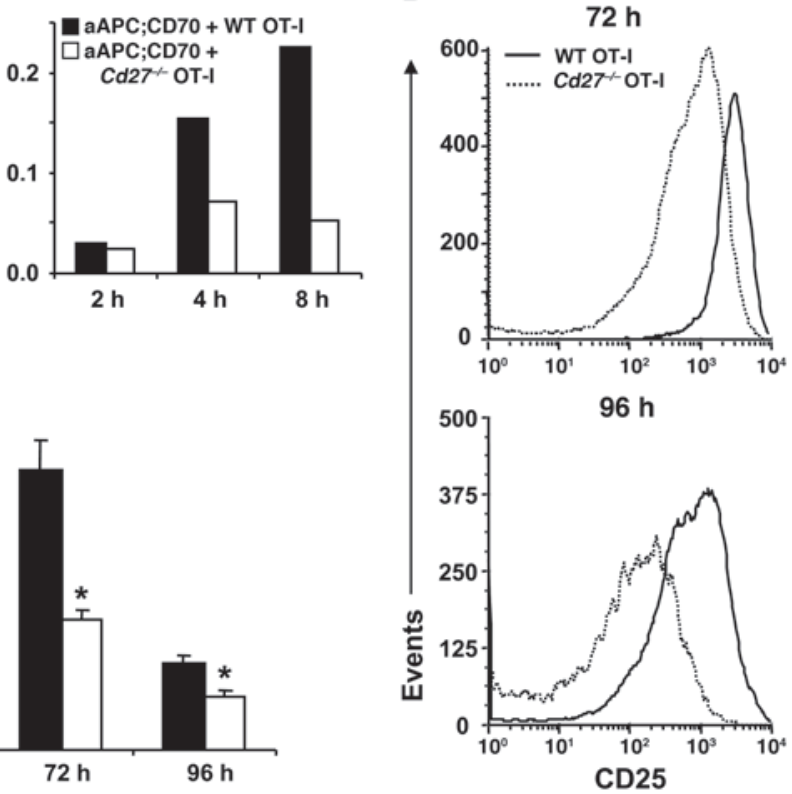

Figure 2

CD27 directs expression of the II2 gene in primed CD8 ${ }^{+} T$ cells. (A) Microarray. OT-I stimulation was performed with CD27 signaling as the variable. In vitro, WT OT-I cells (constant) were stimulated with $\mathrm{CD} 70^{+}$versus $\mathrm{CD} 70^{-}$aAPCs, or WT versus $\mathrm{Cd} 27^{-/-}$were stimulated with $\mathrm{CD} 70^{+}$aAPCs (constant) for the time periods indicated. In vivo, WT versus Cd27-- OT-I T cells were stimulated by OVA immunization and isolated on day 3 or 4 from DLN and spleen. mRNA extracted from OT-I T cells that had or had not received a CD27 signal was cohybridized on the microarrays. A heat map was created to depict the hierarchy of differentially expressed genes according to the mRNA signal intensity (shown as ${ }^{2} \log$ ratio) and the criteria mentioned in Methods. The I/2 gene was the top hit, and its differential expression is shown. Differential Cd27 mRNA expression is shown for validation. (B) Levels of II2 mRNA were determined by quantitative real-time PCR in the indicated samples (as in A) and related to mRNA levels of the household gene Hprt. Data are means of 2 independent reactions. (C) ELISA. WT and $C d 27^{-/-}$OT-I cells were stimulated for the indicated time periods with aAPCs that expressed CD80 and CD70. IL-2 protein was detected in the supernatant by ELISA and expressed in picograms per $10^{6}$ live OT-I cells. Values are mean + SEM of 4 samples. ${ }^{*} P<0.00005$ ( $t$ test). (D) OT-I cells stimulated as in $\mathbf{C}$ were analyzed for CD25 expression by flow cytometry. Data in $\mathbf{C}$ and $\mathbf{D}$ are representative of 2-3 experiments.

tem faithfully corroborated the previously documented pro-survival effect of CD27-CD70 interactions (20) and could be used to determine the underlying molecular mechanism.

$C D 27$ directs expression of the Il 2 gene in primed $C D 8^{+} T$ cells. We performed genome-wide mRNA expression profiling of primed CD8 ${ }^{+}$ OT-I T cells to identify candidate CD27 target genes that might mediate its pro-survival effect. OT-I T cells were stimulated in comparative settings that had only CD27 signaling as a variable. Either WT OT-I T cells were used as responders and CD70 expression on the aAPCs was the variable or WT versus Cd27-/- OT-I
WT vs Cd27 $\div$ OT-I
$\mathrm{T}$ cells were used as responders and CD70 expression on the aAPCs was constant (Figure 2A). The aAPCs were furthermore used in 2 configurations: with and without CD80. In this way, we could examine the consequences of $\mathrm{CD} 27$ stimulation in the presence or absence of $\mathrm{CD} 28$ input and control for possible intrinsic differences between naive WT and Cd27-/- T cells. Gene expression was followed kinetically at 2, 4, 8, and 14 hours after coculture with aAPCs. In addition, gene expression profiling was performed in a comparative setting of WT and Cd27-/- OT-I T cells that had been primed in vivo (Figure 2A). For this purpose, OT-I mice were immunized intranasally with OVA protein, and 3 or 4 days later, $\mathrm{H}-2 \mathrm{~K}^{\mathrm{b}} / \mathrm{OVA}_{257-264}$ tetramer ${ }^{+} \mathrm{T}$ cells from mediastinal DLNs and spleen were flow-cytometrically purified. In all cases, the comparative mRNA samples were cohybridized to oligonucleotide arrays that represented $72 \%$ of all known mouse genes. CD27-regulated genes were identified on the basis of stringent criteria: they had to be differentially expressed with a $P$ value less than 0.00003 and be found in at least 2 different experimental settings. A heat map was constructed that included in the hierarchy the fold differential expression and the number of experimental protocols in which the gene was found to be differentially expressed. In the comparative setting of WT versus Cd27-/-OT-I cells, the Cd27 (Tnfrsf7) gene emerged as most strongly and consistently differentially regulated, confirming the validity of the approach (Figure $2 \mathrm{~A}$ ). This analysis revealed a set of about 30 potential CD27 target genes (data not shown). This set did not include cell cycle regulators, in agreement with the concept that CD27 - at least in mouse $T$ cells - primarily supports cell survival. The set also did not include defined apoptosis regulatory proteins. Interestingly, the Il2 gene emerged from this analysis as the most prominent CD27 target. It was at the top of the heat map and found in all 5 experimental settings, including the in vivo setting (Figure 2A).

The gene array indicated the differential expression of $I l 2 \mathrm{mRNA}$ among $T$ cells that had or had not received a CD27 signal but was not an absolute measure. To assess the contribution of CD27 signaling to the total amount of II2 mRNA produced, we performed quantitative real-time PCR on the mRNA samples of in vitro stimulated OT-I $\mathrm{T}$ cells that has also been used for the gene array experiments. The 
A

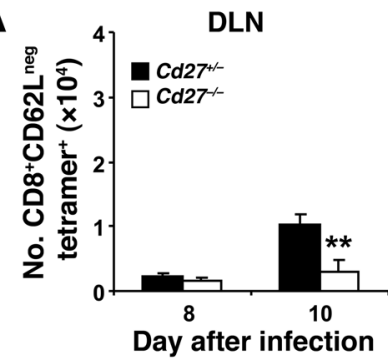

B
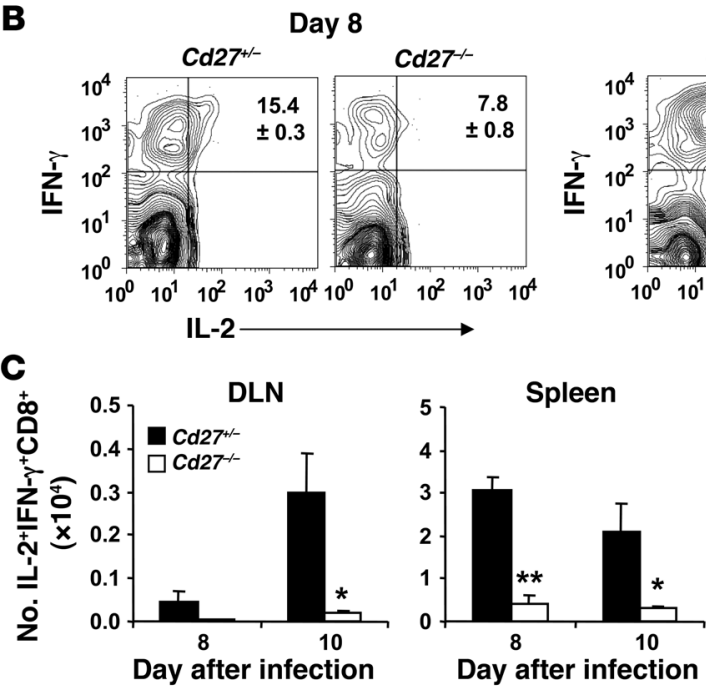

Spleen

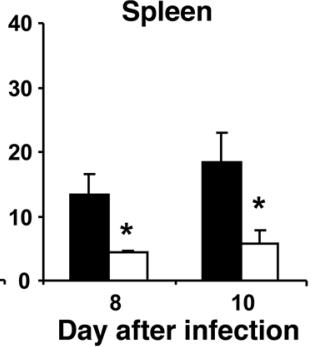

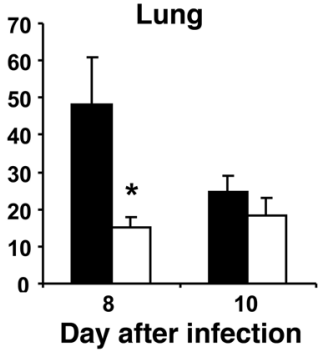

Day 10
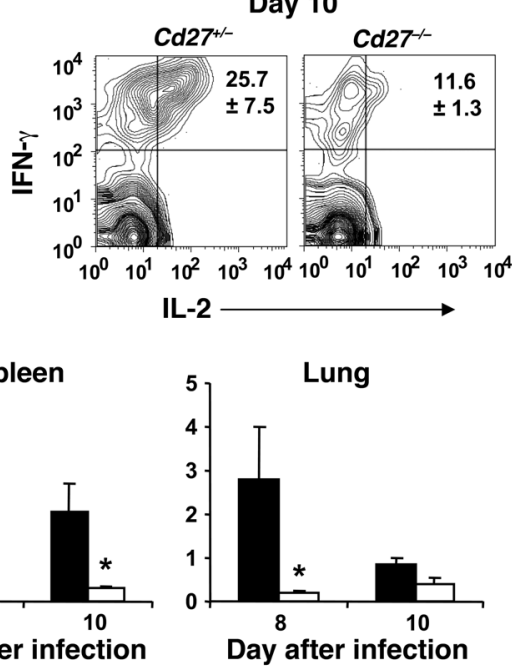

Figure 3

CD27 promotes IL-2 expression in effector CD8+ T cells upon influenza virus infection. $\mathrm{Cd} 27^{+/-}$and $\mathrm{Cd} 27^{-/-}$littermates were infected intranasally with influenza virus, and DLN, spleen, and lung were isolated at day 8 or 10 after infection. (A) The indicated organs were flow cytometrically analyzed for the presence of virus-specific effector $\mathrm{CD}^{+} \mathrm{T}$ cells on the basis of a CD8 ${ }^{+}, \mathrm{CD} \mathrm{L}^{\mathrm{lo} / \mathrm{neg}}, \mathrm{H}-2 \mathrm{D}^{\mathrm{b}} / \mathrm{NP}_{366-374}$ tetramer+ phenotype. Absolute numbers of cells are represented. (B and $\mathbf{C}$ ) Total suspension cells extracted from the indicated organs were restimulated for 4 hours in vitro with $\mathrm{NP}_{366-374}$ peptide; stained for IFN- $\gamma$, IL-2, and CD8; and analyzed by flow cytometry. (B) Representative flow cytometric plot of spleen cells gated on CD8 ${ }^{+} \mathrm{T}$ cells. Numbers indicate the mean percentages $( \pm S E M)$ of IL- $2^{+}$cells within the $\mathrm{CD}^{+}$, IFN- $\gamma^{+}$population. (C) Numbers of IL-2+IFN- $\gamma^{+}$CD8 ${ }^{+}$cells per organ. (A-C) Data are mean \pm SEM from 4 mice. ${ }^{*} P<0.05,{ }^{*} P<0.01$ compared with $\mathrm{Cd} 27^{+/-}$samples ( $t$ test). amount of $I l 2 \mathrm{mRNA}$ produced was related to the amount of mRNA encoding the household enzyme hypoxanthine-guanine phosphoribosyltransferase (HPRT) to standardize the mRNA levels. In a setting with aAPCs that did not express CD80, varying CD70 on the aAPCs or varying CD27 on the responder T cells both revealed that CD27 signaling increased Il2 mRNA production in OT-I T cells, with a gradual increase in $I l 2 \mathrm{mRNA}$ levels over time (Figure 2B). In a setting with aAPCs that did express CD80, CD27 signaling also contributed to $I l 2$ mRNA production (Supplemental Figure 2). However, $I l 2$ mRNA production by $C d 27^{-/-}$OT-I T cells reached higher levels than when only CD70 was present on the aAPCs, indicating that CD28 signaling also contributed. Under the same conditions and in the same time frame, expression of Ifng or Tnf mRNA was not consistently enhanced by CD27 stimulation, indicating that CD27 specifically directed Il2 gene transcription (Supplemental Figure 2).

At the protein level, differential production of IL-2 was detected by ELISA in the supernatants of the OT-I T cells that had been stimulated in the in vitro system. WT OT-I T cells produced significantly more IL-2 than Cd27-/- OT-I T cells at all time points (Figure 2C). This was not due to higher numbers of WT OT-I T cells, since the differential IL-2 production was also found at early time points prior to cell division ( 24 and 48 hours). Moreover, it was expressed per $10^{6}$ live cells. These results indicate that $\mathrm{Cd} 27^{-/-}$ OT-I T cells were deficient in IL-2 production. WT OT-I cells also expressed higher levels of the IL-2 receptor $\alpha$ chain (CD25) than did Cd27-/- OT-I cells at both 72 and 96 hours of culture (Figure 2D). This is in agreement with a documented feed-forward mechanism in which IL-2 upregulates expression of the CD25 gene (11). We conclude that the induction of $I l 2$ gene expression is a prominent function of CD27 on primed $\mathrm{CD}^{+} \mathrm{T}$ cells.
CD27 promotes IL-2 expression in $\mathrm{CD}^{+}$effector T cells after influenza virus infection. To examine whether CD27 promoted IL-2 expression during an immune response in vivo, $C d 27^{+/-}$(control) and $C d 27^{-1-}$ littermates were infected with influenza virus, and 8 or 10 days later, DLN, spleen, and lung were analyzed for virus-specific $\mathrm{CD}^{+} \mathrm{T}$ cells by staining with $\mathrm{H}-2 \mathrm{D}^{\mathrm{b}} / \mathrm{NP}_{366-374}$ tetramers. CD27 deficiency significantly impaired the accumulation of tetramer ${ }^{+}$ $\mathrm{CD}^{+} \mathrm{T}$ cells with a CD62 $\mathrm{L}^{\mathrm{lo} / \text { neg }}$ effector phenotype in DLN, spleen, and lung (Figure 3A), while numbers of tetramer ${ }^{+} \mathrm{CD}^{+} \mathrm{T}$ cells with a CD62 $\mathrm{L}^{\text {hi }}$ naive phenotype were unaffected (data not shown). To detect IL-2 production in effector $\mathrm{CD}^{+} \mathrm{T}$ cells, suspension cells from the indicated organs were restimulated in vitro using $\mathrm{NP}_{366-374}$ peptide and stained for IL-2, together with IFN- $\gamma$ as a marker for virus-specific effector cells, since costaining with tetramers is unsatisfactory (27). Within this virus-specific effector CD8 ${ }^{+}$ $\mathrm{T}$ cell population, the percentage of IL-2-expressing cells was determined. Results of this analysis are shown for spleen, where they revealed that in $\mathrm{Cd} 27^{-/-}$mice the frequency of $\mathrm{IL}^{-} 2^{+}$cells among IFN- $\gamma$-producing effector $\mathrm{CD}^{+} \mathrm{T}$ cells was significantly lower than in control mice (Figure 3B). The combined effects of CD27 signaling on cell numbers and IL-2 production are shown in Figure $3 \mathrm{C}$ as absolute numbers of IL- $2^{+} \mathrm{IFN}-\gamma^{+} \mathrm{CD} 8^{+} \mathrm{T}$ cells in DLN, spleen, and lung. Taken together, these data indicate that CD27 signaling induces IL-2 protein expression in $\mathrm{CD}^{+}$effector $\mathrm{T}$ cells, which is manifest in vivo after influenza virus infection.

CD27 promotes survival of primed $C D 8^{+} T$ cells in vitro via $I L-2 / I L-2$ receptor signaling. IL-2 is an important cytokine that is primarily produced by primed $\mathrm{T}$ cells. It can stimulate cell cycle activity and counteract apoptosis via distinct and partially defined signaling pathways that emerge from the IL-2 receptor $\beta$ and $\gamma$ chains $(2,3)$. 

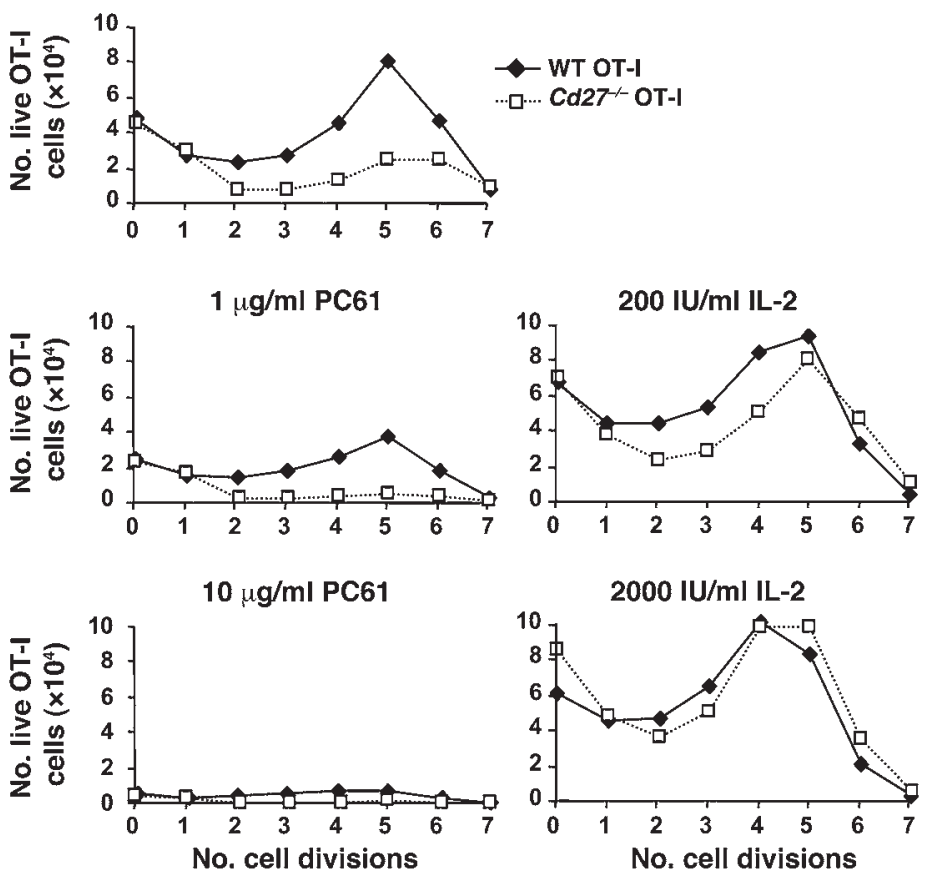

To analyze the contribution of IL-2/IL-2 receptor signaling to $\mathrm{CD} 27$-directed $\mathrm{CD}^{+} \mathrm{T}$ cell survival, we used the in vitro priming system. CFSE-labeled WT and Cd27-/- OT-I T cells were stimulated with aAPCs that expressed CD80 and CD70, and numbers of live OT-I T cells and their division status were read out after 96 hours. As shown above (Figure 1), this system revealed that CD27 signaling promoted the survival of primed OT-I T cells (Figure 4). This survival completely relied on IL-2 receptor signaling, since blocking with anti-IL-2 receptor $\alpha$-chain mAb PC61 at $10 \mu \mathrm{g} / \mathrm{ml}$ completely abrogated live yield of both WT and Cd27-/- OT-I T cells. There was therefore no pro-survival effect of CD27 revealed in this system that was independent of IL-2 receptor signaling. Lack of CD27 on OT-I T cells did not impair the OT-I T cell response as dramatically as complete IL-2 receptor blocking. This indicates that there was a CD27-independent but IL-2-dependent survival signal in the system, which was most likely due to CD28 signaling. Live $C d 27^{-1-}$ OT-I T cell yield was restored to WT levels upon addition of IL-2, in a dose-dependent manner (Figure 4). The results of this complementation approach support the notion that the survival defect of primed $\mathrm{Cd} 27^{-/-} \mathrm{CD}^{+} \mathrm{T}$ cells in this in vitro expansion system is due to deficient IL-2 production.

We also examined the mechanism of survival signaling by CD27 using primary DCs as antigen-presenting cells. Conventional DCs were isolated from spleen, loaded with OVA protein, and simultaneously matured with LPS. Subsequently, they were cocultured with CFSE-labeled naive OT-I T cells. This was done in a control setting and in the presence of blocking anti-CD70 or anti-IL-2 receptor antibody. In addition, we included an agonistic soluble recombinant CD70 protein either alone or in combination with anti-IL-2 receptor antibody. At the 72-hour time point, cell division status of live OT-I T cells was read out (Supplemental Figure 3A). This analysis revealed that also in this in vitro stimulation protocol, CD27-CD70 interactions did not affect cell cycle entry or activity, since CD70 blocking or CD27 stimulation with agonistic CD70 did not alter cell division status. However, the same reagents sig-

\section{Figure 4}

CD27-mediated survival of primed CD8 ${ }^{+} \mathrm{T}$ cells in vitro relies on IL-2/IL-2 receptor signaling. CFSE-labeled WT or Cd27-/- OT-I cells were stimulated with aAPCs expressing CD70 and CD80 in the presence of the indicated amounts of either anti-IL-2 receptor $\alpha$-chain blocking mAb PC61 or recombinant IL-2 (in international units). Ninety-six hours after initiation of stimulation, cells were enumerated, stained with TO-PRO-3, and subjected to flow cytometry. Results are plotted as the absolute number of live OT-I T cells per cell division. Data are mean values of 2 samples and representative of 3 independent experiments.

nificantly altered live cell yield, with the blocking antibody to CD70 reducing it and the agonistic CD70 protein increasing it (Supplemental Figure 3A). CD70 blocking reduced OT-I $\mathrm{T}$ cell survival to a similar extent as IL-2 receptor blocking. Moreover, anti-IL-2 receptor blocking fully abrogated the effect of agonistic CD70. The effects of CD27 stimulation and IL-2 receptor blocking in this model were more modest than when aAPCs were used but were statistically significant. We conclude therefore that also in the context of DCs, survival signaling by CD27 relied on IL-2 receptor signaling.

It was reported previously that - in an in vitro system of OT-I T cell priming in the absence of IL-2-IL-2 receptor interactions - CD27 costimulation prevented downregulation of the IL-7 receptor $\alpha$ chain (CD127) (28). In our experimental protocol, no impact of CD27 on cell surface expression of the IL-7 receptor $\alpha$ chain was observed (Figure $5 \mathrm{~A}$ ). Addition of recombinant IL-7 enhanced the accumulation of live WT and Cd27--- OT-I cells, in agreement with a pro-survival effect of this cytokine on primed CD8 ${ }^{+} \mathrm{T}$ cells (28). However, in contrast to IL-2, IL-7 did not rescue the survival defect of primed $\mathrm{Cd} 27^{-/-} \mathrm{CD} 8^{+} \mathrm{T}$ cells in this in vitro priming system (Figure $5 \mathrm{~B}$ ), underlining the specific role of IL-2 in CD27 costimulation. The collective findings indicate that $\mathrm{CD} 27$ mediates survival of primed $\mathrm{CD}^{+} \mathrm{T}$ cells in this in vitro system by stimulating IL-2 production.

IL2 gene reconstitution rescues accumulation of virus-specific $\mathrm{Cd} 27^{-/-}$ $C D 8^{+}$T cells at the tissue site. As illustrated in Figure 3A, a key phenotype we have documented previously in $C d 27^{-/-}$mice is the defective accumulation of primed $\mathrm{CD}^{+} \mathrm{T}$ cells following intranasal influenza virus infection (19-21). Subsequent experiments by various groups have corroborated the importance of CD27/ CD70-dependent costimulation in mediating accumulation of $\mathrm{CD}^{+}$effector T cells in vivo $(22,29-31)$. The identification of the Il2 gene as a CD27 target gene and the discovery that IL-2 was fully responsible for the pro-survival effect of $\mathrm{CD} 27$ on primed $\mathrm{CD}^{+}$ $\mathrm{T}$ cells in vitro prompted us to test whether it is IL-2 that mediates the CD27-dependent accumulation of effector $\mathrm{CD}^{+} \mathrm{T}$ cells in vivo. For this purpose, we used the F5 mouse strain as donor, since it expresses a transgenic TCR specific for the immunodominant influenza $\mathrm{NP}_{366-374}$ peptide in the context of $\mathrm{H}-2 \mathrm{D}^{\mathrm{b}}$. The IL-2 cDNA was stably expressed in WT or $\mathrm{Cd} 27^{-/-} \mathrm{F} 5 \mathrm{CD}^{+} \mathrm{T}$ cells by retroviral transduction, which required in vitro stimulation with ConA and IL-7. The retroviral vector directed bicistronic expression of GFP or yellow fluorescent protein (YFP), which allowed us to flow-cytometrically sort transduced cells prior to adoptive transfer and to track them in vivo. Sorted cells were transferred into $C d 27^{-/-}$recipient mice, which were subsequently infected with influenza virus. At day 8 after infection, responses were analyzed by flow cytometry and cell counting (Figure 6A). 

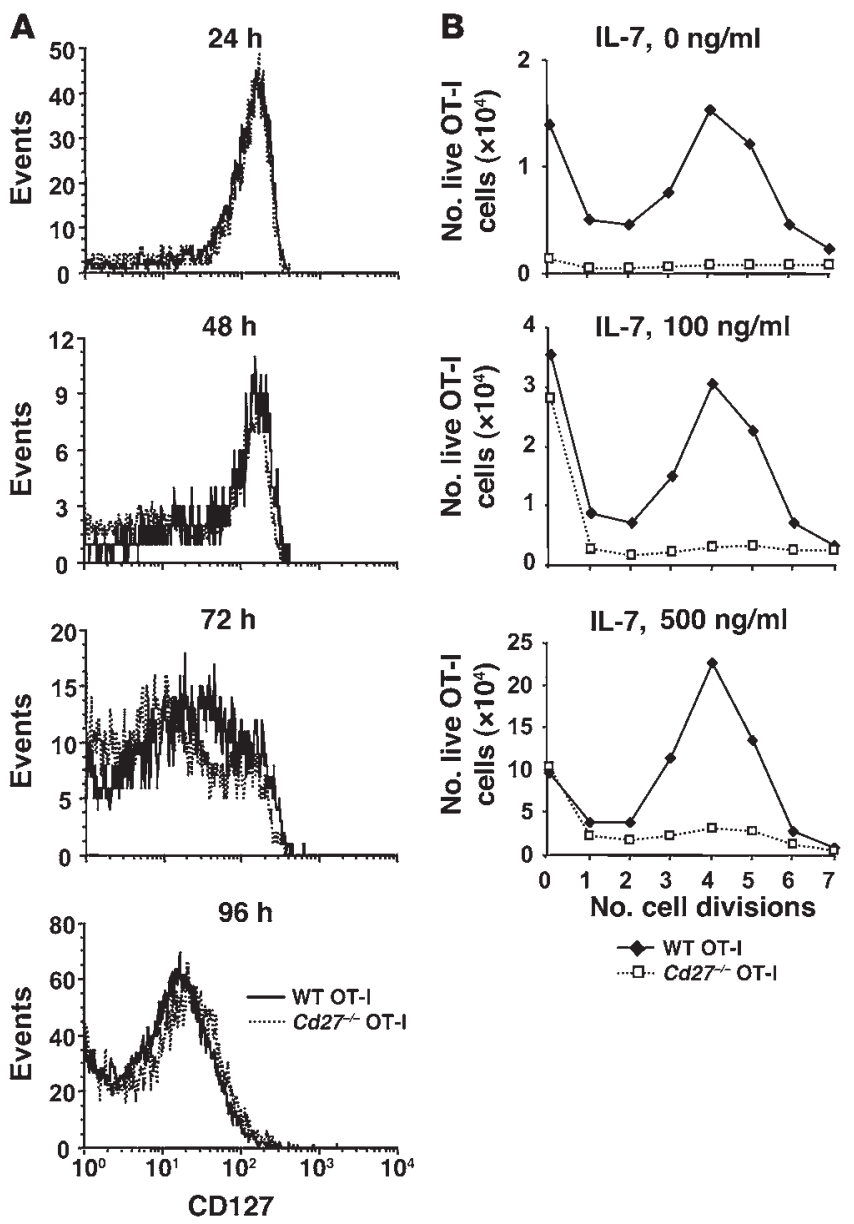

In one experimental protocol, WT F5 T cells were transduced with an empty vector encoding YFP, and $C d 27^{-/-}$F5 T cells were transduced with an empty vector encoding GFP. These cells were mixed at a $1: 1$ ratio and transferred into the same recipient mice. $C d 27^{-/-} \mathrm{F} 5 \mathrm{~T}$ cells transduced with a vector encoding IL- $2_{\text {IRES }} \mathrm{GFP}$ were transferred into different recipient mice. The gating strategy to identify these populations is shown in Figure 6B. Side-by-side comparison revealed that at day 8 after infection, WT F5 T cells had accumulated to significantly higher numbers numbers in DLN, spleen, and lung of the same recipient mice than $\mathrm{Cd} 27^{-/-} \mathrm{F} 5$ $\mathrm{T}$ cells (Figure $6 \mathrm{C}$ ). This indicated that $\mathrm{Cd} 27^{-/-} \mathrm{F} 5 \mathrm{~T}$ cells had a cell-intrinsic defect that could not be restored by neighboring WT cells. Strikingly, IL-2-reconstituted $C d 27^{-/-}$F5 T cells accumulated to WT levels in the lung, indicating that IL-2 could correct their survival defect in this organ (Figure 6C). However, IL-2-reconstitution did not correct the accumulation deficit of $C d 27^{-/-}$F5 T cells in DLN or spleen (Figure 6C). In a second experimental protocol, we compared side-by-side in the same recipients the accumulation of WT F5 cells with empty vector and Cd27- $7^{--}$F5 T cells that had been reconstituted with the IL2 gene. This analysis corroborated that IL2 gene reconstitution restored the accumulation of Cd27 $7^{-1-}$ F5 T cells to WT levels (Figure 6D). Next, we performed an essential control, which was to test whether WT F5 T cells profited from IL2 gene transfer to a similar extent as $C d 27^{-/-}$F5 T cells. Importantly, retroviral IL-2 expression in WT F5 T cells did not alter their accumulation in the lung after influenza virus infection

\section{Figure 5}

No involvement of IL-7 signaling in CD27-mediated survival of primed CD8 ${ }^{+} \mathrm{T}$ cells. (A) WT or $\mathrm{Cd} 27^{-1-} \mathrm{OT}-\mathrm{I}$ cells were stimulated with aAPCs that expressed CD70 and CD80 and were analyzed at the indicated time points after culture for surface expression of the IL-7 receptor $\alpha$-chain (CD127) by flow cytometry. Data shown are representative of 4 independent experiments. (B) CFSE-labeled WT or Cd27-/- OT-I cells were stimulated with aAPCs expressing CD70 and CD80 in the presence of the indicated amounts of recombinant IL-7. Ninety-six hours after initiation of stimulation, cells were enumerated, stained with TO-PRO-3, and subjected to flow cytometry. Results are plotted as the absolute number of live OT-I T cells per division. Data are mean values of 2 samples. The data shown are representative of 2 independent experiments.

(Figure 6E). This indicated that IL2 gene expression specifically complemented CD27 deficiency. The collective data suggest that the defective accumulation of $C d 27^{-/-}$effector $\mathrm{CD}^{+} \mathrm{T}$ cells at the tissue site is due to defective IL-2 production.

CD27 mediates survival at the tissue effector site via an autocrine $I L-2$ pathway. We next examined whether the IL-2 that is ordinarily produced under control of CD27 signaling promotes effector CD8 ${ }^{+}$ $\mathrm{T}$ cell survival via a paracrine or an autocrine mechanism. In this experiment, we also tested whether the effect of IL-2 reconstitution manifested itself on a polyclonal $\mathrm{T}$ cell repertoire. For this purpose, T cells from non-TCR transgenic $C d 27^{-/-}$mice were transduced with the YFP-encoding empty vector or the GFP-encoding vector containing IL-2 cDNA and injected at a 1:1 ratio into $C d 27^{-1-}$ recipient mice (Figure $7 \mathrm{~A}$ ). The question in this case was whether the empty vector-transduced cells would profit from the IL-2 produced by the reconstituted cell population, i.e., whether IL- 2 could act in a paracrine fashion. At day 8 after influenza virus infection, empty vector $\left(\mathrm{YFP}^{+}\right)$and IL-2-expressing $\left(\mathrm{GFP}^{+}\right)$effector $\mathrm{CD}^{+} \mathrm{T}$ cells were enumerated.

In the lung, but not in DLN or spleen, the IL-2-reconstituted $\mathrm{CD}^{+}$effector $\mathrm{T}$ cells accumulated to significantly higher numbers than the empty-vector-transduced cells that were present at the same location (Figure 7B). This experiment confirmed that IL-2 selectively promoted effector $\mathrm{CD}^{+} \mathrm{T}$ cell accumulation at the tissue site and could overcome the survival defect in $\mathrm{Cd} 27^{-1-} \mathrm{T}$ cells. Moreover, it shows that IL- 2 improves effector $\mathrm{CD}^{+} \mathrm{T}$ cell accumulation in the infected tissue via an autocrine mechanism.

\section{Discussion}

In this study, we demonstrate that CD27 instructs primed CD8 ${ }^{+}$ T cells to express IL-2. Provision of IL- 2 in the medium corrected the survival defect of $\mathrm{Cd} 27^{-1-} \mathrm{CD}^{+} \mathrm{T}$ cells in vitro, and genetic reconstitution with the $I L 2$ gene corrected the survival defect of $\mathrm{Cd} 27^{-1-} \mathrm{CD} 8^{+} \mathrm{T}$ cells at the tissue site in vivo. These findings indicate that $\mathrm{CD} 27$ can promote effector $\mathrm{CD}^{+} \mathrm{T}$ cell survival by directing IL-2 production (Figure 7C). After intranasal infection with influenza virus, expression of CD70, 4-1BB ligand, and OX40 ligand is induced on B cells and DCs in the lung (19). This fits with a role of these receptor-ligand interactions in maintaining effector $\mathrm{CD}^{+} \mathrm{T}$ cells at the tissue site. Indeed, we have documented in this model that the accumulation and maintenance of influenza virus-specific $\mathrm{CD}^{+} \mathrm{T}$ cells in the lung throughout the course of an acute infection relied strongly on CD27 signaling and to a lesser extent on 4-1BB. There was also a contribution by OX40, but this was exerted throughout the contraction or memory phase and impacted only virus-specific memory $\mathrm{CD}^{+} \mathrm{T}$ cells numbers 
A
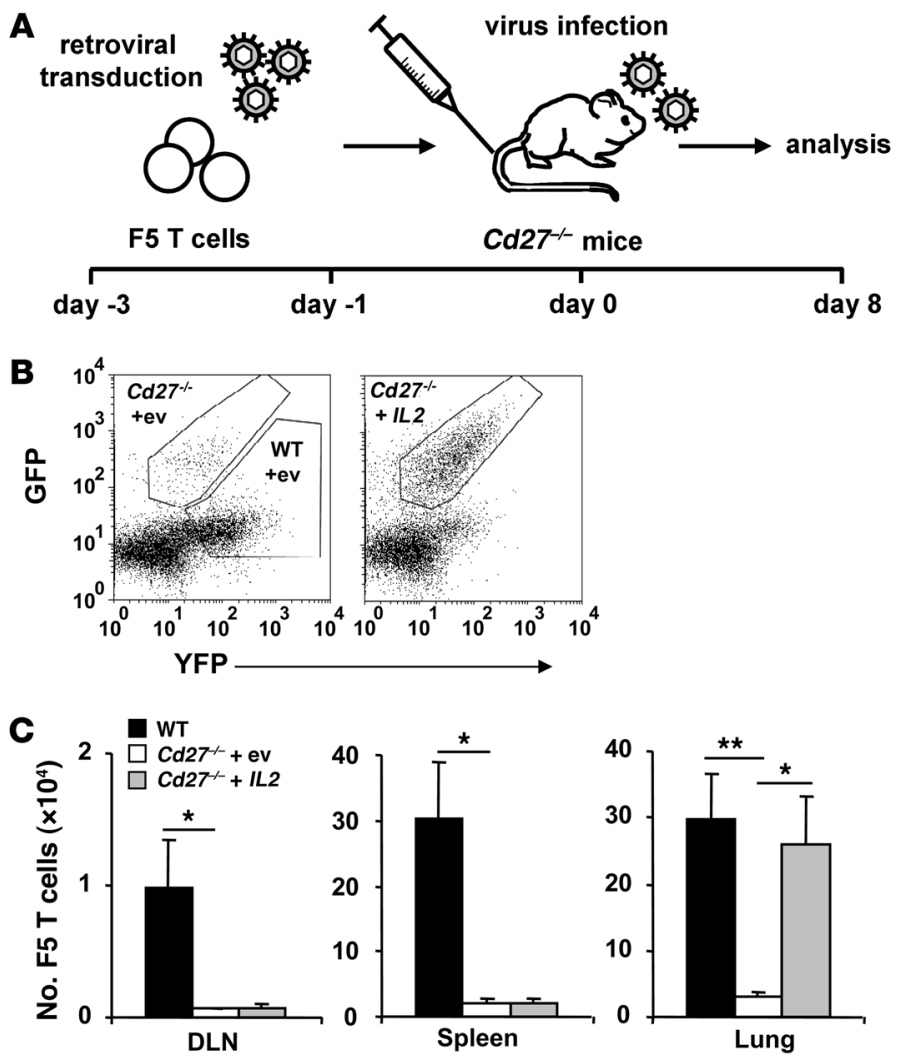

D
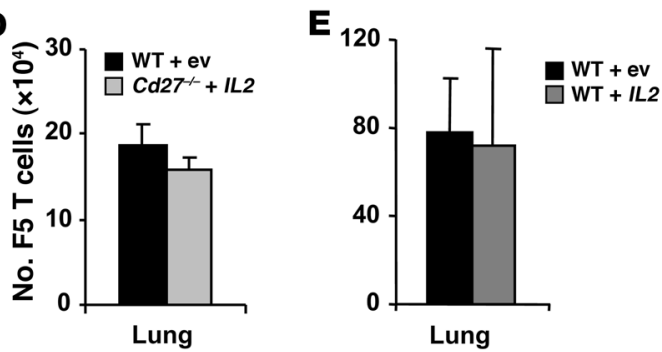

(19). Therefore, among these 3 receptor-ligand systems, the CD27$\mathrm{CD} 70$ system is of the greatest importance for effector $\mathrm{CD} 8^{+} \mathrm{T}$ cell survival at the tissue site in this physiological mode of virus infection. The mechanism by which the closely related TNF receptor family members CD27, 4-1BB, and OX40 support $\mathrm{T}$ cell survival is expected to be similar, given that they employ highly homologous signaling mechanisms (4).

Our data provide a direct connection with the work of D'Souza et al., who studied the relevance of IL-2 production for the primary $\mathrm{CD}^{+} \mathrm{T}$ cell response to viral infection, soluble protein, or tumor antigen in vivo, using T cells from IL-2- or CD25-deficient mice. They showed that regardless of the context of antigen delivery, IL-2 signaling was dispensable for initiation of $\mathrm{CD}^{+} \mathrm{T}$ cell cycling but required for sustained expansion. This requirement was consistently more apparent in nonlymphoid tissue than in secondary lymphoid organs (15). In a follow-up study, they corroborated that autocrine IL-2 dictates the accumulation of virusspecific $\mathrm{CD}^{+} \mathrm{T}$ cells in tertiary, but not lymphoid, tissues (16). Our study reveals that $\mathrm{CD} 27$ is a key factor in directing the autocrine IL-2 production that is required for the survival of effector $\mathrm{CD}^{+} \mathrm{T}$ cells in nonlymphoid tissue.

\section{Figure 6}

IL-2 rescues survival of virus-specific $\mathrm{Cd} 27^{-/-} \mathrm{CD} 8^{+} \mathrm{T}$ cells at the tissue site. (A) Strategy: WT or Cd27-/- influenza virus-specific F5 $T$ cells were retrovirally transduced in vitro with a vector encoding IL-2 IRES GFP or with an empty vector (ev) encoding YFP or GFP only. Transduced F5 T cells were sorted for CD8 and GFP or YFP expression and injected i.v. into $\mathrm{Cd} 27^{-/-}$mice, which were subsequently infected with influenza virus. At day 8 , cells were harvested from DLN, spleen, and lung; enumerated; stained for CD8; and analyzed by flow cytometry. ( $\mathbf{B}$ and $\mathbf{C}$ ) Experimental protocol 1: WT F5 T cells with ev-YFP and $C d 27^{-1-}$ F5 T cells with ev-GFP were mixed at a 1:1 ratio and injected into the same recipient mice (B, left). Cd27-/ F5 T cells with IL-2IRESGFP vector were injected into different recipient mice (B, right). (B) Dot plots show the gating for transduced F5 cells as identified by GFP or YFP expression (in lung). (C) Absolute numbers of $\mathrm{YFP}^{+}$or $\mathrm{GFP}^{+} \mathrm{CD}^{+}$of the indicated genotypes based on flow cytometry as outlined in B. (D) Experimental protocol 2: WT F5 T cells with ev-GFP and WT F5 T cells with IL-2/RESGFP vector were injected into different recipient mice. Absolute numbers of GFP+ $\mathrm{F} 5$ cells are shown. (E) Experimental protocol 3: WT F5 T cells with ev-YFP and Cd27 $7^{--}$F5 T cells with IL-2IRESGFP vector were injected into the same recipient mice. Absolute numbers of GFP + F5 cells are shown. Data are mean + SEM of 4 mice per group. ${ }^{\star} P<0.05,{ }^{* \star} P<0.01$ ( $t$ test).

CD27 deficiency compromised survival of virus-specific effector $\mathrm{CD}^{+} \mathrm{T}$ cells in the lung but also impaired their accumulation in DLN and spleen, as documented here and in our previous work (19-21). Reconstitution with the IL2 gene rescued the survival of these cells in the lung, but not in DLN or spleen. Using the reconstitution approach, we could not conclusively test the relevance of IL-2 for survival of $\mathrm{CD}^{+}$ $\mathrm{T}$ cells in the priming lymphoid organs, since the $\mathrm{T}$ cells used for adoptive transfer were not naive. They had to be activated in vitro to allow for retroviral transduction. Therefore, their requirements for in vivo survival may be different from those of endogenously primed CD8 ${ }^{+} \mathrm{T}$ cells at early stages. Comparing the responses of $\mathrm{Cd} 28^{-/-}$and $C d 27^{-/-} \mathrm{CD}^{+} \mathrm{T}$ cells in DLN of influenza virus-infected mice, we have previously found that CD27 contributed to clonal expansion in the DLN to the same extent as CD28. CFSE labeling indicated that CD27 supported survival of primed $\mathrm{CD} 8^{+} \mathrm{T}$ cells throughout successive divisions after priming (20). Given the available data on the IL-2 independence of initial clonal expansion (13-16), we favor the interpretation that $\mathrm{CD} 27$ supports initial clonal expansion in lymphoid tissues via a mechanism other than autocrine IL-2 production. Our in vitro system was fully IL-2 dependent and was therefore not suitable to study such a mechanism. However, Carr et al. have previously documented an IL-2-independent pathway for CD27/CD70-mediated clonal expansion of CD8 $8^{+}$(OT-I) $\mathrm{T}$ cells in vitro that was revealed in presence of IL-7 (28). They found that CD27 stimulated cell division in this system, which we have not observed using adoptive transfer of CFSE-labeled influenza virus-specific $\mathrm{CD}^{+} \mathrm{T}$ cells in vivo (20). There is evidence that it is not IL-7, but possibly rather IL-15 that plays a role in IL-2-independent clonal expansion at early time points after priming (13). It is hoped that in vitro conditions with a cytokine milieu that approximates the situation in lymphoid organs can be used in the future to investigate the alternative mechanism(s) by which CD27 supports the accumulation of antigen-specific $\mathrm{T}$ cells in priming organs. 

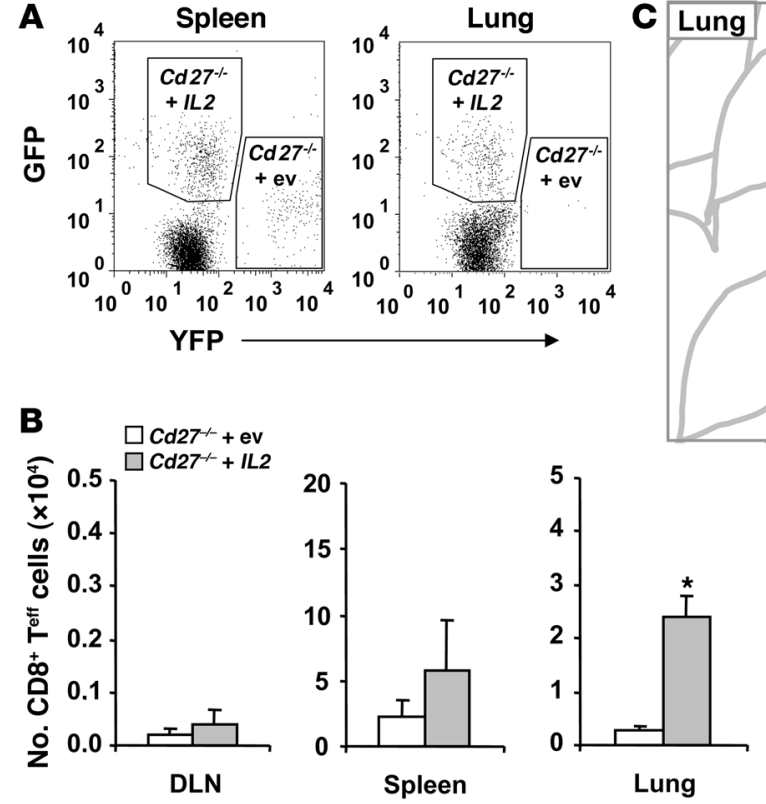

Figure 7

CD27 mediates effector CD8+ T cell survival via an autocrine IL-2 pathway. Nontransgenic Cd27-/ T cells retrovirally transduced with an IL-2IRESGFP vector or ev-YFP were mixed at a $1: 1$ ratio and transferred into $C d 27^{-/-}$mice. At day 8 after influenza virus infection, cells extracted from DLN, spleen, and lung were enumerated, stained with mAb against CD8 and CD62L, and analyzed by flow cytometry. (A) The gating strategy used to detect the indicated cell populations. (B) Absolute numbers of $\mathrm{GFP}^{+}$or $\mathrm{YFP}^{+} \mathrm{CD}^{+} \mathrm{CD}^{+} 2 \mathrm{~L}^{\mathrm{lo} / \mathrm{neg}}$ effector $\mathrm{T}$ cells (Teff). Data are mean + SEM of 3 mice. ${ }^{*} P<0.01$ ( $t$ test). (C) Schematic representation of the CD27-driven autocrine pathway for IL-2 production at the tissue site (lung). CD70 on professional APCs triggers CD27 on the T cell, which induces //2 gene expression. IL-2 drives survival via its receptor (IL-2R) on the same T cells.

Additional work is needed to delineate the intracellular molecular pathways by which CD27 directly or indirectly (via IL-2) can support activated $\mathrm{T}$ cell survival. Gene array analysis did not provide obvious clues with regard to regulation of apoptosis regulatory proteins at the transcriptional level at early time points after priming. However, mRNA expression profiling provides only partial insight in the cellular response, since effects at the posttranslational level are not revealed. Ongoing work indicates that CD27 signaling increases the expression of the antiapoptotic protein $\mathrm{Bcl}-\mathrm{x}_{\mathrm{L}}$, which is in line with findings in human $\mathrm{CD}^{+} \mathrm{T}$ cells (32). Its role in survival signaling by CD27 - be it directly or via IL-2 receptor signaling, which also involves $\mathrm{Bcl}-\mathrm{x}_{\mathrm{L}}$ upregulation (33) - is under investigation.

Carr et al. found that in the absence of IL-2, the clonally expanded cells did not differentiate into IFN- $\gamma$-producing cells (28). From these findings, the authors have proposed a hypothesis that CD27 on $\mathrm{CD}^{+} \mathrm{T}$ cells allows for their development into central memory cells, avoiding the differentiation-inducing effects of IL-2 (34). Our data do not contradict such a scenario, even though it seems counterintuitive, given the identification of the Il2 gene as CD27 target gene. Regardless of the mechanisms involved, it is clear that CD27-CD70 interactions are an important determinant for the formation and secondary expansion of $\mathrm{CD}^{+}$memory $\mathrm{T}$ cells. CD27 deficiency impairs CD8 ${ }^{+}$memory $\mathrm{T}$ cell formation and secondary responsiveness (19). Accordingly, deliberate CD70 expression or soluble agonistic CD70 coun- teracts contraction $(35,36)$. In the human system, loss of CD27 expression is used as a marker for terminally differentiated effector/memory cells (37). In adoptive T cell therapy trials of HIV-infected individuals and in melanoma patients, CD27 expression was a hallmark of the primed $\mathrm{CD}^{+}$ $\mathrm{T}$ cells that survived long term, in contrast to their CD27-negative counterparts (38, 39). Thus, in both human and mouse, CD27 is associated with long-term survival of previously activated $\mathrm{CD}^{+} \mathrm{T}$ cells. In humans, this was also associated with a capacity of $\mathrm{CD} 27^{+} \mathrm{CD}^{+} \mathrm{T}$ cells to secrete IL-2 upon TCR restimulation (38).

The contribution of CD27-CD70 interactions to memory $\mathrm{CD}^{+} \mathrm{T}$ cell formation and secondary responsiveness has been delineated to a significant extent in mouse models and involves contributions of CD27 on the $\mathrm{CD}^{+} \mathrm{T}$ cells themselves, as well as on $\mathrm{CD}^{+} \mathrm{T}$ cells, which can provide help in the memory $\mathrm{CD}^{+} \mathrm{T}$ cell response. In the first place, CD27 deficiency impairs secondary expansion of adoptively transferred memory CD8 ${ }^{+} \mathrm{T}$ cells (19). While this may indicate a requirement for CD27-CD70 interactions during the secondary response, there may also be a role for CD27-CD70 interactions in programming $\mathrm{CD}^{+} \mathrm{T}$ cells for optimal secondary expansion during the primary response (40). Given the proposed role of $\mathrm{IL}_{-2}$ in $\mathrm{CD}^{+}$memory programming (41), it is attractive to speculate that in this scenario, CD27 signaling into $\mathrm{CD}^{+} \mathrm{T}$ cells allows for the required IL-2 production. Under normal conditions of transient CD70 expression on DCs, $\mathrm{CD}^{+} \mathrm{T}$ cells are required for memory programming (42). Interestingly, a link between CD27 and IL-2 production also exists in this case. We have shown that $\mathrm{CD} 27$ on $\mathrm{CD}^{+} \mathrm{T}$ cells is essential for the delivery of $\mathrm{CD}^{+} \mathrm{T}$ cell help and directs IL- 2 production in $\mathrm{CD}^{+} \mathrm{T}$ cells (43). Moreover, CD27 also directs the expression of MS4A4B, a molecule that we have linked to the "helped" status of memory $\mathrm{CD}^{+} \mathrm{T}$ cells and is instrumental in IL-2 production (43). Other researchers have also found a link between CD27 and IL-2 in memory $\mathrm{CD}^{+} \mathrm{T}$ cell programming. They have demonstrated that $\mathrm{CD} 4^{+}$ $\mathrm{T}$ cell help is required for maintenance of CD27 expression on memory $\mathrm{CD}^{+} \mathrm{T}$ cells, which facilitated IL-2 expression upon secondary expansion (44).

The collective data indicate that the IL-2 production that is directed by CD27-CD70 interactions plays an important role in promoting $\mathrm{CD}^{+} \mathrm{T}$ cell immunity to viral and tumor challenge. In particular, its role in the maintenance of effector $\mathrm{CD}^{+} \mathrm{T}$ cells in nonlymphoid tissue and its role in the memory response have important implications not only for vaccination strategies in viral infections but also for the treatment of cancer. This is alluded to by the observation that the size of the $\mathrm{CD} 27^{+} \mathrm{CD} 8^{+} \mathrm{T}$ cell pool in bulk tumor-infiltrating lymphocytes was positively correlated with tumor regression in melanoma patients (39). This knowledge opens up various avenues for therapeutic intervention. 


\section{Methods}

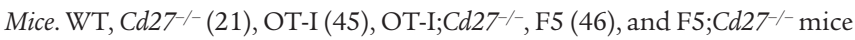
on a $\mathrm{C} 57 \mathrm{BL} / 6$ background were used for experiments at 7-12 weeks of age. OT-I mice express a transgenic TCR with specificity for OVA257-264 peptide in the context of $\mathrm{H}-2 \mathrm{~K}^{\mathrm{b}}$, and F5 mice express a transgenic TCR with specificity for influenza virus $\mathrm{NP}_{366-374}$ peptide in the context of $\mathrm{H}-2 \mathrm{D}^{\mathrm{b}}$. Mice were of the CD45.2 allotype. Experiments were approved by the Experimental Animal Committee of The Netherlands Cancer Institute (DEC) and performed in accordance with national guidelines.

Flow cytometry. Cells were isolated from lungs, spleens, and DLNs and stained with fluorochrome-conjugated antibodies or MHC tetramers as described previously (43). Antibodies used were anti-CD8 $\beta$ (53-6.7), antiCD4 (L3T4), anti-CD70 (FR70), anti-CD80 (16-10A1), Vק5.1/5.2 (MR9-4), anti-CD27 (LG.3A10), anti-CD45.1 (A20), anti-IL-2 (JES6-5H4), anti-IFN- $\gamma$ (XMG1.2), anti-Vß11 (RR3-15), anti-CD25 (PC61), anti-CD127 (A7R34), and anti-CD62L (MEL-14). These mAbs were obtained from BD Biosciences or eBioscience or prepared as purified Ig from available hybridomas. Allophycocyanin-labeled $\mathrm{H}-2 \mathrm{~K}^{\mathrm{b}} / \mathrm{OVA}_{257-264}$ and $\mathrm{H}-2 \mathrm{D}^{\mathrm{b}} / \mathrm{NP}_{366-374}$ tetramers were prepared as described previously (47). Cells were analyzed using a FACSCalibur (BD) or CyAn (Dako) flow cytometer. Data were analyzed with FCS Express (De Novo Software) or FlowJo (Tree Star Inc.) analysis software. Propidium iodide-stained (PI-stained) dead cells were excluded from analysis. OT-I cells used for ex vivo microarray, transduced aAPC lines, and retrovirally transduced $\mathrm{T}$ cells were sorted by flow cytometry (FACSAria, BD) and kept on ice immediately after sorting.

For intracellular staining, single-cell suspensions were stimulated by culture with $\mathrm{NP}_{366-374}$ peptide (sequence: ASNENMDAM, $100 \mu \mathrm{g} / \mathrm{ml}$ ) for 4 hours, in the presence of recombinant human IL-2 (40 U/ml; Chiron) and GolgiPlug ( $1 \mu \mathrm{l} / \mathrm{ml}$; BD Biosciences). After incubation, cells were surface stained for CD8 and CD62L for 30 minutes on ice, washed, incubated in Cytofix/Cytoperm solution (BD Biosciences) for 20 minutes on ice, washed, and stained for IL-2 and IFN- $\gamma$ on ice for 30 minutes.

T cell purification. For in vitro cultures, T cells were purified from spleens of OT-I mice as described previously (43). Purity of the resulting $\mathrm{T}$ cell populations was checked by flow cytometry using anti-TCR V $\beta 5.1 / 5.2$ and anti-CD8 mAbs and was always greater than $90 \%$. For microarray purposes, $\mathrm{T}$ cells were purified after coculture with aAPCs with CD8 MACS beads according to the manufacturer's protocol (Miltenyi Biotec). Purity of the resulting $\mathrm{T}$ cell populations was always greater than $98 \%$.

DC isolation and OT-I culture. Conventional DCs were isolated from spleens of WT mice. First, spleens were cut in small pieces and treated with Collagenase D ( $1 \mathrm{mg} / \mathrm{ml}$; Roche) and DNAse $(0.1 \mathrm{mg} / \mathrm{ml}$; Roche $)$ in RPMI for 20 minutes at room temperature. B220-positive cells (B cells and plasmacytoid DCs) were depleted using Dynabeads (Dynal). From the remaining cells, DCs were isolated using CD11c MACS beads (Miltenyi Biotec). The DCs were incubated with $0.25 \mathrm{mg} / \mathrm{ml}$ OVA (Sigma-Aldrich), $1 \mu \mathrm{g} / \mathrm{ml}$ LPS (SigmaAldrich, 055:B5), and $10 \mu \mathrm{g} / \mathrm{ml}$ anti-CD40 mAb (FGK45) in RPMI with 8\% FCS. Purified DCs and purified CFSE-labeled naive OT-I cells were cocultured at $37^{\circ} \mathrm{C}$ at a $1: 4$ ratio for 72 or 96 hours, in the presence or absence of $10 \mu \mathrm{g} / \mathrm{ml}$ anti-CD70 $\mathrm{mAb}$ FR70, $10 \mu \mathrm{g} / \mathrm{ml}$ anti-IL-2 receptor $\mathrm{mAb}$ PC61, or $2 \mu \mathrm{g} / \mathrm{ml}$ soluble recombinant FcCD70. FcCD70 is a fusion protein of the Fc portion of human IgG1 and amino acids 41-195 representing the extracellular domain of mouse CD70. A cDNA encoding this fusion protein was constructed by P. Schneider (University of Lausanne, Epalinges, Switzerland) on the basis of a publication that described this molecule as a good CD27 agonist (36). The cDNA was used to produce FcCD70 protein in $293 \mathrm{~T}$ human embryonic kidney cells. The protein was purified by affinity chromatography on Protein A Sepharose (GE Healthcare).

Cell culture. For in vitro priming of OT-I T cells, we used MEC.B7.SigOVA cells - mouse fibroblasts expressing a minigene encoding the $\mathrm{OVA}_{257-264}$ epitope, which is presented in the context of $\mathrm{H}-2 \mathrm{~K}^{\mathrm{b}}$. These aAPCs were available in 2 versions, one that does and one that does not express CD80 and provided by M.J. van Stipdonk (Leiden University Medical Center, Leiden, The Netherlands) (26). They were retrovirally transduced to stably express mouse CD70 and GFP from a bicistronic construct and flow cytometrically sorted to isolate lines with highly comparable levels of $\mathrm{H}-2 \mathrm{~K}^{\mathrm{b}}$ expression. Cells were seeded at $10^{5}$ per well in 24-well plates and cultured overnight to form an adherent monolayer. The next day, wells were washed with medium to remove any nonadherent cells or cell debris. OT-I or Cd27-/OT-I T cells that had been labeled with CFSE $(5 \mu \mathrm{M})$, according the manufacturer's protocol (Invitrogen) were added at $0.5 \times 10^{6}$ per well in culture medium, and plates were centrifuged at $900 \mathrm{~g}$ for 1 minute. After 20 hours of coculture, the nonadherent $T$ cells were gently transferred to empty wells and cultured further. At the indicated time points after initial stimulation with the aAPCs, $T$ cell numbers were determined using a CASY cell counter (Scharfe System GmbH). PI or TO-PRO-3 was added and cell division and death were monitored by flow cytometry. Recombinant human IL-2 (Chiron), IL-7 (Peprotech), and the IL-2R $\alpha$ blocking antibody PC61 as purified Ig were used at the indicated concentrations.

Quantitative real-time PCR. Expression of mRNA for IL-2, IFN- $\gamma, \mathrm{TNF}-\alpha$, and HPRT were measured in the samples used for microarray analysis by real-time PCR (Lightcycler 480 Real-Time PCR System; Roche). Fast SYBR Green Master Mix (Applied Biosystems) was used together with 10 ng cDNA template and $1 \mu \mathrm{M}$ oligonucleotides. The oligonucleotides used to amplify the template DNA were $I l 2$ fwd, 5'-AGCAGCTGTTGATGGACCTA-3'; Il2 rev, 5'-CGCAGAGGTCCAAGTTCAT-3'; Ifng fwd, 5'-CCCACAGGTCCAGCGCCAAG-3'; Ifng rev, 5'-CCCACCCCGAATCAGCAGCG-3'; Tnfa fwd, 5'-CAAGGGACAAGGCTGCCCCG-3'; Tnfa rev, 5'-GCAGGGGCTCTTGACGGCAG-3'; Hprt fwd, 5'-CTGGTGAAAAGGACCTCTCG-3'; and Hprt rev, 5'-TGAAGTACTCATTATAGTCAAGGGCA-3'. Levels of mRNA for the household gene Hprt were used for standardization.

ELISA. ELISA was performed in Immuno 96 MicroWell Plates with MaxiSorp surface (Nunc). Wells were coated with purified anti-IL-2 mAb JES6$1 \mathrm{~A} 12$ at $2 \mu \mathrm{g} / \mathrm{ml}$ in PBS as capture antibody. Next, wells were incubated with test culture supernatants. After this, IL-2 was detected with biotinylated JES6-5H4 mAb at $1 \mu \mathrm{g} / \mathrm{ml}$ in PBS with $1 \%$ BSA, followed by streptavidin-conjugated horse radish peroxidase (Sigma-Aldrich) at 1:10,000 in PBS

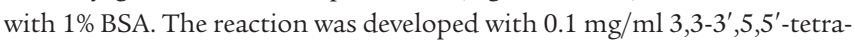
methylbenzidin substrate (Merck) and $0.06 \%$ hydrogen peroxide catalyst in $0.1 \mathrm{M}$ sodium acetate ( $\mathrm{pH}$ 5.5) and stopped with $2 \mathrm{M} \mathrm{H}_{2} \mathrm{SO}_{4}$. OD 450 was read by a Wallac 1420 Victor $^{2}$ multilabel counter (PerkinElmer). A titration curve was created with recombinant murine IL-2 (eBioscience). Incubation steps were performed at room temperature with washing in between.

Constructs. Human IL-2 cDNA was obtained from the German Science Center for Genome Research (RZPD) and cloned into the pMX $\mathrm{IRES}_{\mathrm{GFP}}$ vector (48) using BamHI and NotI restriction enzymes. The pCL-Eco vector encoding the ecotropic retrovirus receptor was obtained from Imgenex Co.

Retroviral transduction. Retroviral packaging of the constructs was performed by cotransfection of $\mathrm{pMX}$-IL2 $2_{\text {IRES }} \mathrm{GFP}$, pMX $\mathrm{IRES}_{\text {IRFP, or }}$ PMX $\mathrm{IRES}_{\mathrm{YFP}}$ together with pCL-Eco into Phoenix-ECO packaging cells (49), using FuGENE 6 (Roche). Supernatant containing retrovirus was collected 48 hours after trans-

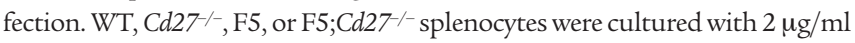
ConA (Omnilabo) and $1 \mathrm{ng} / \mathrm{ml}$ recombinant IL-7 (Peprotech) for 48 hours. For subsequent transduction, they were resuspended in retrovirus-containing medium at $2 \times 10^{6}$ cells in $0.5 \mathrm{ml}$ per well in non-tissue culture-treated 24-well plates (BD Biosciences) coated with $0.5 \mathrm{ml} 50 \mu \mathrm{g} / \mathrm{ml}$ RetroNectin (Takara Bio Inc.). Plates were spun for 90 minutes at $450 \mathrm{~g}$, and cells were cultured for 20 hours and subsequently used for adoptive transfer.

Adoptive transfer. Transduced splenocytes were incubated with allophycocyanin-conjugated anti-CD8 mAb in IMDM with 8\% FCS for 30 minutes 
on ice. Cells were washed and resuspended in IMDM with 2\% FCS and sorted by flow cytometry for GFP or YFP and CD8. The resulting purified transduced $\mathrm{CD}^{+} \mathrm{T}$ cells were suspended in HBSS and injected intravenously into each recipient mouse at the indicated cell number in $100 \mu \mathrm{l}$. In the experiments in Figure 6, $5 \times 10^{3}$ sorted F5 donor cells were injected per experimental group. In the experiment in Figure 7, $5 \times 10^{5}$ sorted nontransgenic donor $\mathrm{T}$ cells were injected per experimental group.

Antigen challenge in vivo. Mice were infected intranasally with 25 hemagglutinin units of influenza virus strain A/NT/60/68 as described previously (19-21). Alternatively, mice were immunized intranasally with $500 \mu \mathrm{g}$ OVA protein plus $1 \mu \mathrm{g}$ cholera toxin (Sigma-Aldrich) in $50 \mu \mathrm{l}$ HBSS (43).

Gene expression profiling. RNA extraction, amplification, and hybridization were performed as described previously (43). Microarrays spotted with the Operon v3 oligonucleotide library were obtained from the central microarray facility of The Netherlands Cancer Institute (http://microarrays.nki.nl). Microarrays were scanned on an Agilent Technologies scanner, and data extraction was done using Imagene 6.0 software (BioDiscovery). Each experiment consisted of 2 microarrays, to allow for dye reversal between the samples, thus reducing systemic errors due to oligonucleotide-specific dye preferences. The heat map in Figure 2A was created using TIGR (The Institute for Genomic Research) MultiExperiment Viewer software, version 3.1. Genes were included in the analysis when found to be differentially expressed with a $P$ value less than 0.00003 in at least 2 different experimental protocols. Hierarchy in this list was determined by the fold differential expression (Mvalue) and the num- ber of experimental protocols in which the gene was found to be differentially expressed. The $P$ value is based on various parameters, including signal intensity (A value), ratio of representation ( $M$ value), and signal quality.

Statistics. Significance in Figures 1-3, 6, and 7 was measured using 2 -tailed Student's $t$ test. Differences were found to be significant when $P$ was less than 0.05 .

\section{Acknowledgments}

We thank personnel of the experimental animal facility, the flow cytometry facility, and the central microarray facility of The Netherlands Cancer Institute for expert technical assistance; M.J. van Stipdonk for aAPCs; P. Schneider for the FcCD70 construct; and J.M. Coquet, T.N.M. Schumacher, and S.H. Naik for critically reading the manuscript. This work was supported by grant 912-04-032 from The Netherlands Organization for Scientific Research (NWO) and grant NKI-2003-2859 from the Dutch Cancer Society.

Received for publication June 15, 2009, and accepted in revised form October 7, 2009.

Address correspondence to: Jannie Borst, Division of Immunology, The Netherlands Cancer Institute, Plesmanlaan 121, 1066 CX Amsterdam, The Netherlands. Phone: 31-20-5122056; Fax: 31-205122057; E-mail: j.borst@nki.nl.
1. Freitas AA, Rocha B. Population biology of lymphocytes: the flight for survival. Annu Rev Immunol. 2000;18:83-111.

2. Keller AM, Borst J. Control of peripheral T cell survival: a delicate division of labor between cytokines and costimulatory molecules. Hum Immunol. 2006;67(6):469-477.

3. Schluns KS, Lefrancois L. Cytokine control of memory T-cell development and survival. Nat Rev Immunol. 2003;3(4):269-279.

4. Watts TH. TNF/TNFR family members in costimulation of T cell responses. Annu Rev Immunol. 2005;23:23-68.

5. Wells AD, Gudmundsdottir H, Turka LA. Following the fate of individual $\mathrm{T}$ cells throughout activation and clonal expansion. Signals from $T$ cell receptor and CD28 differentially regulate the induction and duration of a proliferative response. J Clin Invest. 1997;100(12):3173-3183.

6. Acuto O, Michel F. CD28 co-stimulation: a quantitative support for TCR signalling. Nat Rev Immunol. 2003;3(12):939-951.

7. Steinman RM, Hawiger D, Nussenzweig MC. Tolerogenic dendritic cells. Annu Rev Immunol. 2003;21:685-711.

8. Appleman LJ, Berezovskaya A, Grass I, Boussiotis VA. CD28 costimulation mediates T cell expansion viva IL-2-independent and IL-2-dependent regulation of cell cycle progression. J Immunol. 2000;164(1):144-151.

9. Colombetti S, Basso V, Mueller DL, Mondino A. Prolonged TCR/CD28 engagement drives IL-2 independent $\mathrm{T}$ cell clonal expansion through signaling mediated by the mammalian target of rapamycin. J Immunol. 2006;176(5):2730-2738.

10. Frauwirth KA, Thompson CB. Regulation of T lymphocyte metabolism. J Immunol. 2004; 172(8):4661-4665.

11. Smith KA. The interleukin 2 receptor. Annu Rev Cell Biol. 1989;5:397-425.

12. Malek TR, Yu A, Scibelli P, Lichtenheld MG, Codias EK. Broad programming by IL-2 receptor signaling for extended growth to multiple cytokines and functional maturation of antigen-activated $T$ cells. J Immunol. 2001;166(3):1675-1683.

13. Li XC, et al. IL-15 and IL-2: a matter of life and death for T cells in vivo. Nat Med. 2001;7(1):114-118.

14. Wong P, Pamer EG. Disparate in vitro and in vivo requirements for IL-2 during antigen-independent CD8 T cell expansion. J Immunol. 2004; 172(4):2171-2176.

15. D'Souza WN, Lefrancois L. IL-2 is not required for the initiation of CD8 $\mathrm{T}$ cell cycling but sustains expansion. J Immunol. 2003;171(11):5727-5735.

16. D’Souza WN, Schluns KS, Masopust D, Lefrancois L. Essential role for IL-2 in the regulation of antiviral extralymphoid CD8 T cell responses. J Immunol. 2002;168(11):5566-5572.

17. Aggarwal BB. Nuclear factor-kappaB: the enemy within. Cancer Cell. 2004;6(3):203-208.

18 . Song J, et al. The costimulation-regulated duration of PKB controls T cell longevity. Nat Immunol. 2004;5(2):150-158.

19. Hendriks J, et al. During viral infection of the respiratory tract, $\mathrm{CD} 27,4-1 \mathrm{BB}$, and $\mathrm{OX} 40$ collectively determine formation of $\mathrm{CD}^{+}$memory $\mathrm{T}$ cells and their capacity for secondary expansion. J Immunol. 2005;175(3):1665-1676.

20. Hendriks J, Xiao Y, Borst J. CD27 promotes survival of activated T cells and complements CD28 in generation and establishment of the effector $\mathrm{T}$ cell pool. J Exp Med. 2003;198(9):1369-1380.

21. Hendriks J, et al. CD27 is required for generation and long-term maintenance of $\mathrm{T}$ cell immunity. Nat Immunol. 2000;1(5):433-440.

22. Schildknecht A, Miescher I, Yagita $H$, van den Broek M. 2007. Priming of $\mathrm{CD}^{+} \mathrm{T}$ cell responses by pathogens typically depends on CD70-mediated interactions with dendritic cells. Eur J Immunol. 2007;37(3):716-728.

23. Keller AM, Schildknecht A, Xiao Y, van den Broek $\mathrm{M}$, Borst J. Expression of costimulatory ligand CD70 on steady-state dendritic cells breaks CD8 ${ }^{+}$ $\mathrm{T}$ cell tolerance and permits effective immunity. Immunity. 2008;29(6):934-946.

24. Arens R, et al. Constitutive CD27/CD70 interaction induces expansion of effector-type $\mathrm{T}$ cells and results in IFN $\gamma$-mediated B cell depletion. Immunity. 2001;15(5):801-812.

25. Tesselaar $\mathrm{K}$, et al. Lethal $\mathrm{T}$ cell immunodeficiency induced by chronic costimulation via CD27-CD70 interactions. Nat Immunol. 2003;4(1):49-54.
26. Van Stipdonk MJ, Lemmens EE, Schoenberger SP. Naïve CTLs require a single brief period of antigenic stimulation for clonal expansion and differentiation. Nat Immunol. 2001;2(5):423-429.

27. Denton AE, Doherty PC, Turner SJ, La Gruta NL. IL-18, but not IL-12, is required for optimal cytokine production by influenza virus-specific $\mathrm{CD8}^{+}$T cells. Eur J Immunol. 2007;37(2):368-375.

28. Carr JM, et al. CD27 mediates interleukin-2-independent clonal expansion of the $\mathrm{CD}^{+} \mathrm{T}$ cell without effector differentiation. Proc Natl Acad SciUS A. 2006;103(51):19454-19459.

29. Taraban VY, Rowley TF, Al-Shamkhani A. Cutting edge: a critical role for CD70 in CD8 T cell priming by CD40-licensed APCs. J Immunol. 2004;173(11):6542-6546.

30. Bullock TN, Yagita H. Induction of CD70 on dendritic cells through CD40 or TLR stimulation contributes to the development of $\mathrm{CD}^{+} \mathrm{T}$ cell responses in the absence of $\mathrm{CD} 4^{+} \mathrm{T}$ cells. J Immunol. 2005;174(2):710-717.

31. Yamada A, et al. CD70 signaling is critical for CD28-independent $\mathrm{CD}^{+} \mathrm{T}$ cell-mediated alloimmune responses in vivo. J Immunol. 2005; 174(3):1357-1364.

32. Van Oosterwijk MF, et al. CD27-CD70 interactions sensitise naive $\mathrm{CD}^{+} \mathrm{T}$ cells for IL-12-induced Th1 cell development. Int Immunol. 2007;19(6):713-718.

33. Gonzalez-Garcia A, Merida I, Martinez AC, Carrera AC. Intermediate affinity interleukin-2 receptor mediates survival via a phosphoinositol 3-kinase-dependent pathway. J Biol Chem. 1997; 272(15):10220-10226.

34. Fearon DT, et al. The rationale for the IL-2-independent generation of the self-renewing central memory CD8 ${ }^{+} \mathrm{T}$ cells. Immunol Rev. June 2006; 211:104-118.

35. Arens R, et al. Tumor rejection induced by CD70mediated quantitative and qualitative effects on effector $\mathrm{CDB}^{+} \mathrm{T}$ cell formation. J Exp Med. 2004; 199(11):1595-1605.

36. Rowley TF, Al-Shamkhani A. Stimulation by soluble CD70 promotes strong primary and secondary $\mathrm{CD}^{+}$cytotoxic $\mathrm{T}$ cell responses in vivo. J Immunol. 2004;172(10):6039-6046.

37. Van Lier RA, ten Berge IJ, Gamadia LE. Human 
CD8+ T cell differentiation in response to viruses. Nat Rev Immunol. 2003;3(12):931-939.

38. Ochsenbein AF, et al. CD27 expression promotes long-term survival of functional effector-memory $\mathrm{CD}^{+}$cytotoxic T lymphocytes in HIV-infected individuals. J Exp Med. 2004;200(11):1407-1417.

39. Huang J, et al. Modulation by IL-2 of CD70 and $\mathrm{CD} 27$ expression on $\mathrm{CD}^{+} \mathrm{T}$ cells: importance for the therapeutic effectiveness of cell transfer immunotherapy. J Immunol. 2006;176(12):7726-7735.

40. Keller AM, Xiao Y, Peperzak V, Naik SH, Borst $\mathrm{J}$. Costimulatory ligand CD70 allows induction of $\mathrm{CD8}^{+} \mathrm{T}$ cell immunity by immature dendritic cells in a vaccination setting. Blood. 2009;
113(21):5167-5175.

41. Williams MA, Tyznik AJ, Bevan MJ. Interleukin-2 signals during priming are required for secondary expansion of $\mathrm{CD}^{+}$memory $\mathrm{T}$ cells. Nature. 2006;441(7095):890-893.

42. Bevan MJ. Helping the CD8 ${ }^{+}$T-cell response. Nat Rev Immunol. 2004;4(8):595-602.

43. Xiao Y, Peperzak V, Keller AM, Borst J. CD27 instructs CD4 $\mathrm{T}$ cells to provide help for the memory CD8 $\mathrm{T}$ cell response after protein immunization. J Immunol. 2008;181(2):1071-1082.

44. Matter MS, Claus C, Ochsenbein AF. CD4 ${ }^{+} \mathrm{T}$ cell help improves $\mathrm{CD}^{+} \mathrm{T}$ cell memory by retained $\mathrm{CD} 27$ expression. Eur J Immunol. 2008;38(7):1847-1856.
45. Hogquist KA, et al. T cell receptor antagonist peptides induce positive selection. Cell. 1994;76(1):17-27.

46. Mamalaki C, et al. Positive and negative selection in transgenic mice expressing a $\mathrm{T}$-cell receptor specific for influenza nucleoprotein and endogenous superantigen. Dev Immunol. 1993;3(3):159-174.

47. Altman JD, et al. Phenotypic analysis of antigen-specific T lymphocytes. Science. 1996;274(5284):94-96.

48. Kitamura T, et al. Retrovirus-mediated gene transfer and expression cloning: powerful tools in functional genetics. Exp Hematol. 2003;31(11):1007-1014.

49. Kinsella TM, Nolan GP. Episomal vectors rapidly and stably produce high-titer recombinant retrovirus. Hum Gene Ther. 1996;7(12):1405-1413. 